\title{
TIEMPO Y NOVELA EN LA NOCHE DE LOS TIEMPOS DE MUÑOZ MOLINA
}

\author{
ANTONIO UnZUÉ \\ IES Santiago Sobrequés (Girona) \\ aunzue@xtec.cat
}

\section{RESUMEN}

El tratamiento del tiempo constituye un elemento clave en la última novela de Antonio Muñoz Molina. El análisis de los diferentes niveles cronológicos, que desde el momento presente se remontan a las raíces de la guerra civil, junto con el estudio de la frecuencia y el ritmo, permite valorar un aspecto determinante en la configuración del texto como artefacto narrativo y artístico. Asimismo, contribuye a interpretar la aportación del escritor al debate sobre la memoria histórica.

Palabras Clave: Muñoz Molina, Tiempo de guerras perdidas, tiempo narrativo, memoria histórica.

\section{RÉSUMÉ}

L'emploi du temps devient un aspect décisif dans le dernier roman d'Antonio Muñoz Molina. L'analyse des différents niveaux chronologiques, que à partir de l'actualité reviennent en arrière vers les racines de la guerre civile espagnole, et de la fréquence et du rythme, permet de mettre en valeur un trait déterminant dans la configuration de ce texte en tant que création narrative et artistique. De même, cette analyse permet d'interpréter le point de vue de l'écrivain par rapport au débat de la mémoire historique.

Mots-CLEF: Muñoz Molina, Tiempo de guerras perdidas, temps narratif, mémoire historique. 
Como subrayan numerosos teóricos de la novela ${ }^{1}$, el tiempo constituye un elemento clave dentro de la construcción del relato, en la medida en que aparece como condición necesaria, junto con el espacio y los personajes, para el desarrollo de la secuencia narrativa.

Si esto es así para cualquier novela, en La noche de los tiempos de Antonio Muñoz Molina (2009) el vector temporal alcanza un papel clave, no sólo para la configuración del relato como construcción narrativa, sino en cuanto elemento fundamental de la obra como propuesta artística e ideológica. El mismo título de la novela incide en este factor temporal, jugando con diferentes líneas de significado que se entrecruzan. Por una parte, sin duda la «noche de los tiempos» alude a ese pasado que engulle los destinos de los protagonistas del relato (2009: 958). El autor imagina, desde la perspectiva actual, la peripecia de algunos personajes marcados por la guerra civil española y el exilio, luchando con las dificultades que implica la distancia temporal. Con la expresión «la noche de los tiempos», el autor enfatiza, por consiguiente, el reto que supone construir un relato verosímil ambientado en una ya época lejana. Acercarse a estas vidas es remontarse a un pasado casi olvidado, a la «noche de los tiempos». Asimismo, no puede obviarse en el título una referencia valorativa al desastre de la guerra civil y las consecuencias que supone para la vida de los personajes y del país ${ }^{2}$.

El estudio del orden temporal, la frecuencia y el ritmo permite valorar una de las aportaciones destacadas de esta novela como creación literaria. La opción por una estructuración cronológica compleja, que juega constantemente con varios niveles temporales; la técnica reiterativa en la presentación de los acontecimientos, que incorpora matices y permite graduar la tensión narrativa; la morosidad en el tratamiento de numerosas secuencias, que imprime al texto un tipo de lectura pausada; todos estos aspectos configuran una apuesta literaria muy personal, en las antípodas de la literatura de consumo. Por otra parte, las numerosas muestras de autor implícito, perceptibles en esa primera persona que aparece esporádicamente en el relato y en numerosas apreciaciones que marcan la interpretación de los acontecimientos, no resultan en absoluto extrañas para el público lector de Muñoz Molina, cuyo horizonte de expectativas está marcado, sin duda, por la figura del escritor derrotado en Beatus ille o la visión de los exilios y del fanatismo ideológico del siglo XX en Sefarad.

\section{EL TIEMPO DEL RELATO: EXTENSIÓN, ORDEN, FRECUENCIA Y RITMO}

La noche de los tiempos se organiza en torno a cuatro referencias temporales básicas: el presente del narrador, que funciona como un trasunto del autor y por tanto se sitúa en la actualidad; las dos horas de viaje en tren que realiza el protagonista, el arquitecto Ignacio Abel, una tarde de octubre de 1936 desde Nueva York a la estación de Rhineberg, adonde vendrán a buscarlo para conducirlo al college en el que comenzará una nueva etapa; la vida del protagonista, desde septiembre de 1935 , cuando conoce a la que será su

\footnotetext{
${ }^{1}$ Por su atención a la cuestión cronológica, seguiré especialmente las obras de Genette $(1989,1998)$ y Bal (1987).

${ }^{2}$ Como dice Antonio Astorga en $A B C$, los protagonistas de esta novela pasan de la normalidad a la catástrofe en pocos días, de la vida cotidiana a "la noche de los tiempos" (2009: 4).
} 
amante, Judith Biely, hasta la huida al extranjero de aquél en octubre de 1936; finalmente, una última instancia temporal, que recupera las infancias respectivas de los dos amantes, así como las trayectorias vitales de otros personajes.

Se trata, por tanto, de una trama compleja que busca introducir gradualmente al lector en un relato inserto en un contexto histórico muy conflictivo, un marco temporal cuyas claves se despachan en otras obras sin demasiados matices. Es justamente esto lo que ese narrador intenta evitar. Para ello, desde el momento presente identifica una figura entre la masa de viajeros de la estación de Pennsylvania:

Lo veo primero de lejos, entre la multitud de la hora punta, una figura masculina idéntica a las otras, como en una fotografía de entonces, empequeñecida por la escala inmensa de la arquitectura (...). (2009: 11)

Esa mirada se acerca paulatinamente al personaje hasta convertirlo en su referencia central. Al final del relato, su vida, y la de quienes lo rodean, quedará nuevamente transferida a la multitud de donde salió, a esa «noche de los tiempos» que todo lo engulle (2009: 958). El rescate, sin embargo, nos habrá permitido conocer la trayectoria personal del protagonista y su entorno, una peripecia en la que pueden adivinarse coincidencias con la vida de algunos intelectuales prominentes de la II República, como el mismo Pedro Salinas. De este modo, la ficción narrativa permite un acercamiento al período histórico a través de una figura de gran interés por su perfil contradictorio y asistir en primera fila al hundimiento de un proyecto vital y cívico ${ }^{3}$.

La presencia de esta voz narrativa innominada aparece de vez en cuando en el relato, matizando la historia desde una mirada externa. En el primer capítulo, donde se ofrecen las coordenadas básicas de la narración, asoma varias veces esta primera persona: «lo he visto cada vez con más claridad» (2009:12), «los voy viendo surgir ante mí» (12), «indago en su conciencia igual que en sus bolsillos o en el interior de su maleta» (13), «lo he visto afeitándose, frente al espejo del lavabo, esta mañana» (18). De este modo, queda claro que se trata de una referencia externa, omnisciente, que puntea la historia con una visión distanciada. Así, en el capítulo tercero, esa voz subraya la naturalidad con que imagina el encuentro de Ignacio Abel y Moreno Villa: «no me cuesta nada imaginar a los dos hombres conversando» (69). Pero es una voz que se oculta, recordando al lector de vez en cuando su presencia a través de breves indicaciones, como la referencia al calzado de Ignacio Abel en el capítulo 7: «veo sus zapatos negros cuarteados» (160), o la evocación de Judith Biely: «la veo más claramente ahora» (179), en el mismo capítulo. Avanzado el relato, en el capítulo 24, vuelve a aparecer este narrador externo, haciendo explícito el sentido de su intervención:

Quiero imaginar con la precisión de lo vivido lo que ha sucedido veinte años antes de que yo naciera y lo que dentro de no muchos años ya no recordará nadie: el brillo de esos pocos

\footnotetext{
${ }^{3}$ A este respecto, las citas de Manuel Azaña y de Pedro Salinas que figuran como preliminar en la novela reflejan la perplejidad de los testigos directos del desastre ante la evidencia del fracaso. La novela de Muñoz Molina permite visualizar este sentimiento.
} 
días de julio en la distancia y la negrura del tiempo, esa tarde precisa, los días que la han precedido; y para hacerlo de verdad necesitaría algo tan imposible como la clarividencia de un pasado anterior a la propia memoria: necesitaría la inocencia sobre el porvenir, la ignorancia absoluta sobre lo que ya es inminente (...) Pero quién podrá adelantar la mano traspasando la frontera del tiempo; tocar las cosas, no sólo imaginarlas (...). (2009: 575-576)

Esta cita, en efecto, es fundamental no sólo para entender la función de ese narrador externo que comparece de vez en cuando en el relato, sino para descubrir el objetivo del relato como evocación histórica: el intento de revivir las sensaciones de una serie de personajes arrastrados por el torbellino de la guerra. Se trata, ciertamente, de una tarea difícil, como el propio narrador subraya, pues pretende dar el testimonio de una cotidianidad trastocada sin haberla conocido de primera mano.

Por otra parte, la indicación de los veinte años que separan los hechos de 1936 y el nacimiento del narrador confirma la asociación de la figura narrativa con el autor, si bien en ningún momento llegan a desarrollarse más aspectos relativos a la personalidad del narrador-autor. Tal vez en ello, más que una identificación explícita con el escritor, lo que se pretende es poner de relieve la dificultad objetiva de la evocación, la distancia que separa la España del 36 y la actualidad, desde la perspectiva de quien no ha tenido un conocimiento directo de los hechos históricos. Lejos de la actitud de quienes ven aquella época tan convulsa desde la seguridad de sus trincheras ideológicas, Muñoz Molina prefiere recordarnos los límites de su evocación. Para él, la novela no es un instrumento de combate ideológico, sino un intento de entender la hecatombe general a través de las existencias de varios personajes. Es así, con los mecanismos de la ficción, como el autor nos ofrece una lúcida reflexión sobre la época.

La figura del narrador-autor se oculta hasta los capítulos 28 y 29, en los que vuelve a aparecer para subrayar esa distancia que le separa del tiempo del enunciado:

Detrás del ventanal en el pasadizo elevado, Philip van Doren sonríe al reconocerlo, lo ve volverse hacia el otro, el profesor Stevens, director del departamento de Fine Arts and Arquitecture (...). Dos hombres vistos desde lejos, desde arriba, unidos por una vaga semejanza de época, en una estación muy secundaria, en la orilla del río Hudson, una tarde de octubre de hace setenta y tres años. (2009: 673)

Sin necesitar la presencia de la primera persona, el narrador amplía el zoom y recalca de este modo la perspectiva del lector actual, esa perspectiva que supone entre aquellos personajes que se encuentran en Rhineberg una curiosa similitud. El mismo narrador recorre ahora Madrid en busca del número 7 de la calle Marqués de Duero, donde imagina el encuentro entre Ignacio Abel y Rafael Alberti (719). Asimismo, es capaz de ocupar el lugar de Abel ante Bergamín: «casi puedo verlo, como si fuera yo quien se ha sentado delante de él» (720). Eso le permite reconstruir también las últimas horas del arquitecto por Madrid en octubre de 1936:

Qué raro imaginar con tanta claridad lo que yo no he vivido, lo que sucedía hace más de setenta años, la plaza con el campamento de toldos y chabolas entre los setos, alrededor de la estatua ecuestre de Felipe IV (...). (2009: 812) 
La evocación atiende a los detalles menudos que permiten captar la cualidad de la vida, esos detalles en los que no se entretienen los manuales de historia, si bien componen el tejido de la cotidianidad. No será, sin embargo, hasta el final de la novela cuando vuelva a insistirse en esa distancia que separa el mundo del receptor y el tiempo del enunciado, con la mención de un sobre en el que los nombres de Ignacio y Judith irán desdibujándose «según esta noche de finales de octubre de 1936 vaya quedándose en un pasado cada vez más lejano» (946). No obstante, la distancia no impide la irrupción de esa primera persona narrativa en los momentos previos a la despedida: «la veo de perfil, más nítida según va amaneciendo, incorporada contra el respaldo de la cama, ahora inquieta» (958).

El segundo nivel cronológico del relato se centra en el viaje de dos horas que el protagonista emprende al comienzo de la narración rumbo al que será su nuevo destino laboral. Se trata de una línea temporal que avanza lentamente a lo largo de buena parte de la narración, mientras el narrador refiere el último año de la vida de Ignacio Abel en España. Así pues, si bien la estampa del protagonista a punto de subir al tren en octubre de 1936, hacia las cuatro menos diez de la tarde, constituye el arranque del relato, en los capítulos siguientes el narrador sólo recuerda esta circunstancia de forma esporádica, marcando lentamente el avance cronológico a través de indicaciones diversas: «echado hacia atrás en el asiento del tren que empieza a ponerse en marcha» (42), «según el tren empieza a moverse la breve serenidad de Ignacio Abel se ha convertido en alarma» (75), «ese hombre que apoya la cara contra la ventanilla del tren mirando la anchura del río Hudson» (160), «pero sobre todo se abandona al ímpetu del tren» (181), «adormecido por el ritmo del tren ha visto a sus hijos en el relámpago de un sueño de colores» (305), «el olor del Atlántico entrando en ella tan poderosamente como entra ahora el del Hudson por la ventanilla del tren»(404), «tan cerca del final y del desastre, piensa ahora en el tren, río Hudson arriba» (555).

Las referencias al trayecto en tren son escasas, las suficientes para recordar al lector ese segundo marco temporal, mientras se desarrolla la historia de amor de Ignacio Abel y Judith Biely. Poco a poco, el tren se acerca a su destino, «esa pequeña ciudad que en menos de una hora dejará de ser solo un nombre, Rhineberg» (537). El anuncio de la estación donde lo esperan (567) pone en guardia al protagonista y desencadena una reflexión sobre el sentido de su huida, que no deja de parecerle una especie de deserción. La inminencia de la llegada se prolonga varios capítulos, hasta el 28, pero sólo a partir del capítulo 32 el eje central de la acción pasará a situarse en este nivel cronológico, desarrollando así la secuencia del recibimiento en el college y el posterior reencuentro con Judith. En definitiva, a partir del capítulo 2, el relato mantiene en un segundo término el viaje del protagonista durante esas dos horas de tren, hasta que la progresión del tercer nivel cronológico recupera el motivo inicial para dar curso al desenlace de la historia.

El tercer nivel cronológico de la novela se sitúa entre septiembre de 1935 y octubre del año siguiente. El relato sigue una progresión temporal salpicada de numerosas interrupciones que, desde esta perspectiva, alcanzan la consideración de prolepsis, cuando refieren acontecimientos situados en planos posteriores, y analepsis, cuando recuperan vivencias previas, circunstancia que compone un cuarto nivel cronológico. No obstante, 
este tercer nivel constituye la referencia principal de la historia. Ya en los capítulos segundo y tercero, el narrador refiere el primer encuentro de los amantes en septiembre de 1935, al que sigue otro el 7 de octubre con motivo de la conferencia de Ignacio Abel en la Residencia de Estudiantes (108). La fiesta en la casa madrileña de Van Doren, en el mismo mes de octubre, constituye el punto de partida de la relación, según se indica en el capítulo sexto. Tras el reencuentro, las citas menudean esos días: el paseo por el Jardín Botánico, el primer beso en el reservado del hotel Florida. Pero en el mismo capítulo 8 en el que arranca su relación, el narrador, a modo de contrapunto, adelanta alguna información sobre el inquietante accidente de Adela, la esposa de Ignacio Abel, que sucede en junio del año siguiente. La farsa de la vida cotidiana continúa, como se indica en el capítulo 9, en el que el protagonista asiste en octubre a un encuentro familiar en la sierra. El capítulo 12 avanza unos meses hasta llegar a diciembre de 1935 y luego febrero de 1936, marcando el progreso de una relación construida a partir de encuentros furtivos por la ciudad. La escena del paseo solitario de Judith por el Madrid en el que Ignacio vivió su infancia acaba con una llamada telefónica intempestiva a su casa, en demanda de ayuda. Este asunto, que ocupa buena parte de los capítulos 12 y 13, rompe el muro que separa la doble vida del protagonista y advierte de la fragilidad de la relación. Ya en el capítulo 13, a través de una prolepsis, el narrador adelanta el final de la historia:

Tan soberanamente como había decidido hacerse su amante una tarde de principios de octubre en Madrid decidió dejar de serlo algo más de ocho meses después, hacia mediados de julio, con una seca determinación americana (...). (308)

Los capítulos siguientes avanzan subrayando la creciente tensión social y política a partir de las elecciones de febrero del 36, que dan el poder al Frente Popular. El desorden y los atentados de signo diverso se suceden, en un contexto que afecta también a la convivencia familiar, como se aprecia en la deriva fascista de Víctor. En el capítulo 16, la tensión se hace tan fuerte que el protagonista contempla la salida del país como la única forma de superar la situación. Paradójicamente, la escapada de fin de semana a Cádiz, relatada en el capítulo 17, marca la etapa final de la relación de Ignacio y Judith, el momento en que el tiempo y la culpa comienzan a romper la ilusión de una vida paralela. La entrevista de Abel y Negrín, situada en mayo del 36, insiste en la salida de España como solución al problema personal del arquitecto. Poco después, en los capítulos 19, 20 y 21, alcanza especial relevancia la figura de Adela y su intento de suicidio. El supuesto accidente, ubicado en junio, acelerará la decisión de Judith de romper con Ignacio. En el capítulo 23 se interrumpe momentáneamente el desarrollo cronológico adelantando el viaje del protagonista a Nueva York, pero en el capítulo siguiente el relato retoma el hilo argumental tras la ruptura de los amantes, consignando la recuperación de Adela en la sierra y la deserción final de Ignacio, el 19 de julio, cuando sube al tren que lo separará definitivamente de su familia.

Los capítulos 25 y 26, que desarrollan un papel central en la historia, muestran la búsqueda de Judith por Madrid el atardecer del 19 de julio. Tras la morosidad con que se presentan las primeras horas posteriores al golpe franquista, la acción se acelera en los capítulos siguientes con escenas significativas como el asesinato del dueño del taller o la detención de Ignacio, en ese mismo mes; el encuentro casual con el profesor Rossman, 
en agosto; o su búsqueda, en septiembre, asunto que ocupa los capítulos 29, 30 y 31. El viaje a Illescas para rescatar el patrimonio artístico en peligro constituye una secuencia reveladora del contexto político y social. La etapa madrileña termina con una serie de visitas del protagonista a Negrín, Moreno Villa y al presidente Azaña, que marcan por contraste el significado de su deserción. En este mismo capítulo 32, en que concluye la vida del protagonista en Madrid, el narrador sitúa una escena clave en la historia, relatada ahora por extenso, después de haber sido anunciada en varias ocasiones; una escena que implica la ruptura definitiva de Abel con su familia política. La salida del protagonista hacia el extranjero permite la conexión de los niveles cronológicos tercero y segundo, con el relato de su paso por Francia y Nueva York.

La construcción narrativa de la novela incorpora esporádicamente un cuarto nivel temporal. Se trata del conjunto de evocaciones que recuperan el pasado de diferentes personajes, interrumpiendo la acción y dándole profundidad. Así, en el capítulo 4 el narrador evoca algunos recuerdos infantiles del protagonista vinculados a la portería materna (78), los encuentros con el profesor Rossman en Weimar en 1923 y Barcelona en 1929 (88-89). Son recuperaciones narrativas que funcionan como analepsis completivas. El carácter reiterativo del relato se observa, por ejemplo, en la ampliación de la secuencia en la que se explica la estancia en Alemania del protagonista, momento que supone un punto de inflexión notable en su crecimiento profesional y personal, como se aprecia en el capítulo 6. El mismo procedimiento se observa en el capítulo 7 en torno a la figura de Judith Biely: su origen inmigrante, los sacrificios de su madre, el matrimonio fracasado, el deseo de superar en Europa las oportunidades perdidas (169-177). Esta recuperación tiene continuidad en el capítulo 10, en el que el narrador amplía el retrato de la protagonista femenina, haciendo hincapié en su deseo de superar las limitaciones del entorno, siguiendo su propio testimonio (231-246). Este proceso de recuperación prosigue en el capítulo 11, refiriendo en forma contrapuntística la infancia solitaria de Ignacio y la cambiante relación con Lita y Miguel, sus hijos.

La presencia de analepsis completivas decae conforme avanza el relato. Sin embargo, en el capítulo 18 destaca la secuencia en la que el narrador presenta al protagonista repasando el álbum familiar, lo que permite reproducir la historia personal de Adela, una figura clave en el relato. Esta escena sirve además de pórtico a la secuencia en la que se narra su intento de suicidio. A partir de este momento se hacen menos frecuentes las retrospecciones, salvo algunas evocaciones muy significativas. Así, en el capítulo 33, estando ya el protagonista instalado en la casa de invitados del college, el narrador rememora una visita de Manuel Azaña a la Ciudad Universitaria madrileña en 1932, cuando era presidente del Consejo, en compañía de Juan Negrín. En el capítulo siguiente, el narrador recupera uno de los encuentros furtivos de Ignacio y Judith en la facultad de Filosofía de Madrid en marzo de 1936. La llegada de Judith Biely al college implica la evocación de algunas escenas de especial significado, como el asesinato en julio de 1936 del general López Ochoa en Madrid (907), el arresto de Ignacio en la capital española (928), las explicaciones de Judith y su madre en ese verano (938-939), la estancia de los amantes en Cádiz (949) o la infancia solitaria de Ignacio (955-957). En definitiva, la irrupción de este cuarto nivel cronológico, siendo más habitual en los capítulos iniciales, se mantiene de forma esporádica en toda la novela a través de pequeñas evocaciones que alteran la línea cronológica básica. 
De hecho, una de las características más marcadas de esta novela es, justamente, la confluencia de distintas líneas cronológicas que, partiendo del momento de la publicación del relato, componen la historia de estos personajes rescatados de la barahúnda de la guerra. Por supuesto, el eje cronológico fundamental es el que refiere la relación de Ignacio y Judith desde septiembre de 1935 hasta el verano de 1936, pero este marco temporal, como se ha señalado, aparece interrumpido por numerosos avances y retrocesos, lo cual redunda en la configuración de un ritmo muy particular y en la construcción de un significado textual en el que el tiempo tiene un papel clave. ${ }^{4}$

En toda novela la cuestión de la frecuencia narrativa tiene su importancia, no en vano se trata de un asunto central en el paso de la fábula a la historia, en términos de Bal $(1987)^{5}$. Algún ejemplo de La noche de los tiempos nos permitirá apreciar la técnica reiterativa empleada por el autor y sus efectos en el relato. Así, la evocación de la infancia del protagonista se verifica en ampliaciones sucesivas. Ya en el capítulo 4 se alude a la soledad del protagonista en la portería materna (78). Este mismo sótano materno reaparece en el capítulo 11, en contraste con la niñez privilegiada de su propios hijos, Miguel y Lita (257). Más adelante se alude también al trabajo infantil de Ignacio, como ayudante de Eutimio (263-264). El contraste entre el presente acomodado y la precariedad de su niñez queda confirmado con la secuencia en la que se refiere la muerte en 1903 del padre, en accidente de trabajo (267). Se trata de una escena clave que refleja, por una parte, el origen humilde de Ignacio Abel y su determinación de prosperar, y por otra, su desclasamiento. Más adelante, la figura de Eutimio significará la recuperación de esas vivencias infantiles del protagonista, tan alejadas de su vida de arquitecto de prestigio (389). La expedición a Illescas, donde encuentra a Miguel Gómez, el hijo de Eutimio (772-773), evoca ese pasado humilde de Ignacio Abel, del que pudo salir por su esfuerzo y el sacrificio de sus padres. Al final de la novela, el narrador rememora nuevamente la infancia del protagonista, vinculada al espacio agobiante de la portería (955-956). El autor procede, como se ha señalado, a partir de ampliaciones sucesivas, que marcan con claridad el contraste entre la infancia del personaje principal y la de sus hijos, a la vez que subrayan la difícil posición de aquél, dividido entre su condición de miembro de la elite del país, unido además por matrimonio a la clase dominante, y sus orígenes proletarios.

La misma técnica reiterativa se aprecia en otros momentos de la novela. Es lo que sucede, por ejemplo, en la petición de socorro de Víctor, el hermano de Adela. Ya en el capítulo 1 se alude al requerimiento del cuñado, que Ignacio desatiende (15), una llamada que reaparece en sueños de manera obsesiva (29). La progresiva implicación del cuñado en actividades subversivas permite imaginar las dificultades de su permanencia en la capital una vez estallada la guerra, a la vez que explica el distanciamiento entre él e Ignacio, sobre todo a raíz de la escena en que, vestido de falangista, Víctor enseña el arma a su so-

\footnotetext{
${ }^{4}$ A este respecto, Jorge Carrión afirma: "La metáfora fluvial sintoniza con la forma en que Muñoz Molina administra la temporalidad de su relato. No se trata de una novela lineal: los saltos temporales son continuos. Pero el lector no pierde jamás de vista en qué punto de la narración se encuentra." (Carrión, 2009: 55)

${ }^{5} \mathrm{El}$ análisis de la frecuencia narrativa sigue un esquema bastante similar en Figuras III de Genette (1989: 172-218) y en Teoría de la narrativa de Bal (1987:85-87). En ambas obras, se subraya la distancia entre los acontecimientos como componentes del desarrollo lógico o cronológico del argumento o fábula y su transformación en historia, como resultado de la construcción narrativa.
} 
brino Miguel (355). El desprecio de Ignacio por su cuñado, relacionado más con el carácter de éste que con su militancia política (369), queda de manifiesto en la escena de la bofetada (370-372), en la que el descubrimiento de los parecidos entre tío y sobrino no hace sino estimular la rabia del padre. El enfrentamiento entre ambos se agudiza tras el intento de suicidio de Adela, que Víctor relaciona con la actitud de su cuñado (521). En un encuentro casual el 19 de julio, Ignacio intenta convencer a Víctor de la conveniencia de reunirse con su familia en la sierra, pero él parece decidido a no escucharlo, obsesionado con su misión salvadora de la patria (631-632). Esta escena queda grabada en la mente de Ignacio como el preludio de la desgracia (655). Un nuevo encuentro con el cuñado confirma su implicación política con la Falange y el peligro que corre en Madrid (718-719). Todo esto permite predecir la reacción de Ignacio cuando aquél acude a pedirle ayuda. Esa voz que ya había comparecido en el primer capítulo queda definitivamente identificada, así como la cobardía de Ignacio, su miedo a perder la posibilidad de salir de España por la aparición de su cuñado (829-831). El sentimiento de culpa de Ignacio, la conciencia de su cobardía y mezquindad, se asocian, sin duda, a esta escena (909-910), de ahí su presentación paulatina, que comienza ya en el primer capítulo, se prepara a partir de referencias indirectas durante el relato, se desvela en el capítulo 32 y es objeto de una valoración en el capítulo 35 .

Para la consideración del ritmo narrativo, conviene tener en cuenta no sólo el tipo de secuencia dominante (resumen, escena, tempo lento, elipsis), sino también el género discursivo en el que se presenta (narración, diálogo, descripción... $)^{6}$. De entrada, podría apuntarse una primera consideración de carácter general: el tono del relato viene marcado por esas dos horas de espera que el protagonista ocupa viajando desde Nueva York hasta la estación de Rhineberg. Se trata de un factor de tensión narrativa que abarca desde el primer capítulo hasta bien avanzada la novela, en el capítulo 28: más de seiscientas páginas para explicar un viaje de dos horas. Naturalmente, en esas dos horas el narrador rememora todo un año de la vida de los protagonistas. Este factor de tensión narrativa se combina, en el plano cronológico inferior en el que se relata la historia de Ignacio y Judith, con una sabia integración de dos modelos rítmicos, uno marcado por la presentación escénica y otro por la elipsis. En numerosos capítulos puede constatarse la inclusión de al menos una secuencia escénica, que funciona como elemento central de la unidad narrativa. Así, en los primeros capítulos, el narrador se demora en la presentación del encuentro y las primeras entrevistas de los protagonistas. En el capítulo 5, por ejemplo, se da cuenta al lector, en forma de presentación escénica, de la conferencia pronunciada por Ignacio Abel en la Residencia de Estudiantes, secuencia de la que el lector recuerda, particularmente, la actitud de Ignacio, la llegada intempestiva de Judith o el contraste entre ella y Adela.

A este respecto, hay algunas escenas clave en la novela. Por un lado, ciertas entrevistas de Ignacio con Negrín (capítulos 18 y 32), Moreno Villa $(3,32)$ y el presidente Azaña (32), en las que puede observarse el choque entre las aspiraciones personales del protagonista y la situación general del país. Por otro lado, de vez en

\footnotetext{
${ }^{6}$ Como en los casos anteriores, para el ritmo seguiré también el modelo planteado por Genette $(1989,1998)$ y Bal (1987).
} 
cuando, el narrador combina presentaciones escénicas más breves en torno a un núcleo temático, trabadas por elipsis narrativas. Es lo que sucede, por ejemplo, en el capítulo 4, en el que el narrador refiere tres momentos de su relación con el doctor Rossman: en los tiempos de estudiante en Alemania en 1923, durante la visita a la exposición de Barcelona en 1929 y en 1935, cuando el profesor llega a España huyendo del comunismo y del nazismo. Esta construcción a base de pequeñas secuencias narrativas sincopadas constituye el recurso predominante en el cuarto nivel del relato, aquel que evoca recuerdos infantiles u otros referidos a los años previos al encuentre de Ignacio y Judith.

Así pues, la combinación de presentación escénica y de elipsis está en la base de la construcción narrativa de esta novela. De este modo, los acontecimientos correspondientes al eje temporal que comprende desde el encuentro de los amantes hasta su separación aparecen referidos a partir de ciertas secuencias clave soldadas entre sí con frecuentes elipsis. Pero en esta distribución rítmica alcanza una incidencia central el asunto relatado en los capítulos 25, 26 y 27. Frente a la discontinuidad dominante en el resto del relato, que refiere la historia con numerosos cortes, en estos capítulos se presenta una secuencia clave en la vida del protagonista: el abandono de la familia en la sierra y la búsqueda desesperada de Judith por el Madrid del 19 de julio de 1936. El narrador se demora en la consignación de las idas y venidas del protagonista por una ciudad en la que se palpa el dramatismo del momento. Es una secuencia central en el relato y su ritmo moroso parece pensado para forzar la reflexión del lector sobre la situación enloquecida de la ciudad.

En definitiva, el ritmo del relato tiende a la morosidad. A este efecto, el diálogo y los fragmentos descriptivos tienen reservado un papel relevante. Así, en la secuencia de la conferencia en la Residencia de Estudiantes, el narrador se demora en el contraste entre Judith y Adela. No es sino una muestra de una tendencia observable en numerosos fragmentos de la historia. Esta morosidad, de forma paradójica, queda confirmada en los capítulos finales, una vez Ignacio Abel llega a Rhineberg. En un momento en que cabría esperar una aceleración narrativa después de la larga espera a que ha sido sometido el lector, la acción parece estancarse, a pesar de la llegada inesperada de Judith, por la tendencia a la profundización psicológica. Todo lo cual no hace sino confirmar una de las características centrales de esta novela, la opción por un ritmo moroso, característico, por otro lado, de la escritura de Muñoz Molina.

\section{LA INCIDENCIA DEL TIEMPO EN EL RELATO}

El tratamiento del tiempo en esta novela presenta tres vertientes destacadas que conviene comentar: la reflexión metaliteraria sobre el tiempo, su vivencia íntima y la relación entre tiempo e historia.

Por una parte, el propio título de la novela ofrece una clara orientación metanarrativa: el objetivo del relato parece ser el rescate de una serie de historias individuales, salvadas de la noche de los tiempos. De ahí la frecuente presencia de indicaciones sobre la cuestión. Así, al hilo del relato, se señala la íntima conexión entre los acontecimientos y su contexto inmediato, pues «nada sucede en tiempo abstracto ni en un espacio en blanco». (22) Pero ese contexto de los personajes, que el autor ha recons- 
truido en un presente ${ }^{7}$ en el que su suerte todavía no está decidida, queda muy lejos de la experiencia del propio escritor y del lector. De ahí la insistencia en rescatar el detalle cotidiano: la ropa, los billetes, los perfumes, las calles... Como se ha indicado al presentar la estructura cronológica de la novela, el narrador subraya la distancia que lo separa de aquella época, que sólo podrá salvar con el poder de la imaginación.

A menudo, los comentarios del narrador inciden también en la inconsistencia de las certidumbres que sustentan la vida cotidiana, un asunto central en esta historia:

Los ojos de Ignacio Abel han visto cosas que el hombre de la fotografía no sospecha. Su seguridad es petulancia; peor aún: ceguera. A un paso de la irrupción del porvenir que lo trastornará todo no intuye su cercanía y no sabe imaginar su espanto. (2009: 26)

La realidad presenta, en efecto, una apariencia engañosa de estabilidad, pues los acontecimientos trastocarán radicalmente la vida cotidiana de los personajes. (35).

La abundancia de reflexiones metanarrativas en los primeros capítulos del relato tiene una función textual clara: preparar al lector para los acontecimientos que se presentarán y para su interpretación. De la misma forma, el epílogo de la novela incide en la cuestión: los protagonistas vuelven al anonimato de donde han sido rescatados, a ese «porvenir ignorado y perdido en la gran noche de los tiempos» (958). En realidad, sus vidas no son sino una muestra de la riada humana arrastrada por el torbellino de la guerra.

El tiempo, por otra parte, constituye un factor clave de la vivencia interna de los personajes. Así, abundan las indicaciones sobre la percepción del tiempo. Ignacio Abel siente la aceleración del tiempo poco antes de subir al tren (24) y se muestra consciente de la trascendencia del momento, pues «en el descuido de un segundo está contenida entera una catástrofe» (25). El protagonista se ve escindido entre la vivencia del presente y un pasado que lo asalta inopinadamente:

Recuerdos súbitos se proyectan ante su mirada en el presente como fotogramas insertados por error en el montaje de una película, y aunque sabe que son falsos no tiene manera de disiparlos y eludir así su promesa y su veneno. (31)

Los recuerdos del pasado se vuelven tan lejanos «como si pertenecieran a otro hombre» (41). Lo sucedido hace un año forma parte de otra vida, de otra época (196). Así, la escisión interna del protagonista es una constante: de la misma manera que su reloj marca las 4 al subir al tren en Nueva York, en su mente todavía rige la hora de Madrid (77); igualmente, durante los meses de su relación con Judith, el autor vive dos vidas paralelas, dos tiempos simultáneos (225). En cierta manera, a pesar de su edad, cree vivir «por equivocación la vida de otro hombre» (456). Se trata de una situación que acaba revelándose como insostenible. Por una parte, ni él ni Judith podrán esquivar la culpa, por mucho que en su aparente inconsciencia hubieran logrado demorar su irrupción (279). Por otro lado, la obsesión por la fugacidad del tiempo, que se les escapa como unos gra-

\footnotetext{
${ }^{7} \mathrm{El}$ escritor destaca en diferentes entrevistas, por una parte, la construcción del relato en torno a un presente que refleja la cotidianidad de los personajes y, por otra, la elección de una voz en primera persona que, desde el momento de la escritura, evoca un pasado que nunca pudo conocer. (Ayén, 2009: 32)
} 
nos de arena en la mano (405), tiñe la alegría de esos días salvados de la cotidianidad en Cádiz, conscientes de que viven «asediados por acreedores, por ladrones y por mendigos de tiempo» (406). A este respecto, la expresión «time in our hands», tiempo a manos llenas (404), se repite como un leitmotiv que subraya justamente el desgaste de la relación de los protagonistas.

Pero tal vez el aspecto que más destaca en la novela es la imbricación de estos tiempos humanos con el tiempo histórico. La plasmación de ese momento decisivo en la historia de España, el año previo a la guerra civil y los primeros meses del conflicto, constituye uno de los atractivos principales del relato.

Esta novela participa de pleno en el debate sobre las relaciones entre la ficción y la Historia. La guerra civil como materia de ficción narrativa es casi un subgénero dentro de la literatura española y no puede decirse que su vitalidad haya decrecido. Más bien parece experimentar en estos momentos un resurgimiento a propósito del debate sobre la memoria histórica. Los autores que ahora se ocupan de la guerra no la han vivido directamente y eso queda reflejado en esta novela a través de ese narrador innominado que, en primera persona, intenta imaginar unas vidas y un contexto que no pudo conocer de forma directa. Estos comentarios, que cuestionan la certeza de la voz narrativa, inciden naturalmente en la verosimilitud de la ficción, en cuanto que sitúan al narrador a la altura del lector, lejos de la seguridad discursiva de quien cree tener la clave del asunto.

El autor, a través de una ficción ubicada en el Madrid de los meses previos a la guerra y de los primeros momentos del conflicto, se ocupa de una realidad muy concreta, la vida cotidiana en la capital de la República, y lo hace subrayando algunos aspectos dolorosos y contradictorios del momento, un tanto a contracorriente del discurso justificador de ciertos sectores ${ }^{8}$.

En primer lugar, el novelista destaca la íntima similitud de los totalitarismos desarrollados en el siglo XX. A través de la peripecia del profesor Rossman, el lector percibe las conexiones entre ideologías tan opuestas como el comunismo y el nazismo. El trágico final del profesor revela la actitud totalitaria de ciertos movimientos de la izquierda radical durante la guerra (788). Este asunto constituye, sin duda, un eje temático fundamental en la novela y los ejemplos de ello son abundantísimos. Así, las manifestaciones de masas que el profesor Rossman conoce en Berlín tienen mucho en común con las concentraciones moscovitas, al igual que el acoso policial del cual es víctima en ambos lugares. Estos excesos los volverá a padecer posteriormente en Madrid, donde será hostigado por los guardianes de la ortodoxia política. Ciertamente, la vida en la capital española se convierte en una aventura imprevisible ya antes de la sublevación de julio: los crímenes políticos de uno y otro bando menudean, la inseguridad en forma de tiroteos descontrolados va en aumento, el temor a la ruptura de las garantías republicanas se hace cada vez más evidente...

Al estallar la guerra, las autoridades se ven incapaces de controlar la seguridad en la calle, por lo que ese ámbito queda en manos de grupúsculos armados que atemorizan a cualquier sospechoso de vinculación con la burguesía. El propio presidente Azaña,

\footnotetext{
${ }^{8}$ Darío Villanueva subraya el interés del escritor por contribuir a la recuperación de la memoria histórica, denunciando la amenaza de manipulación maniquea sobre la guerra civil. (2010)
} 
según se indica en el relato (825), no puede evitar que las ejecuciones próximas a su residencia oficial lo desvelen de madrugada. Los fusilamientos en las inmediaciones de la Residencia de Estudiantes (748) constituyen el reverso de esa visión idílica de la lucha antifascista, como también sucede con la anécdota atribuida a Juan Negrín, que recurre a su influencia política para salvar de la muerte a su hermano fraile (729).

A este respecto, los capítulos centrales en los que el protagonista sigue infructuosamente la pista de Judith Biely por Madrid el 19 de julio, constituyen una muestra evidente de los excesos que el autor quiere destacar: las detenciones arbitrarias de cualquier persona de aspecto burgués (601), las soflamas totalitarias (617), la iglesia en llamas $(618,627)$, los comercios asaltados (629), el descontrol gubernamental (635-636). Al día siguiente, el proceso continúa: el asesinato del dueño del taller (658), el registro del domicilio y la detención de Ignacio Abel (658-666), que no acaba con su fusilamiento por la intervención de Eutimio Gómez en el último momento.

En el relato, junto con la atención a estos aspectos incómodos de la retaguardia, el autor introduce, a través de ciertos personajes clave, algunas reflexiones que funcionan con indicadores evidentes de autor implícito. Me refiero, particularmente, a los comentarios de Negrín ${ }^{9}$, Azaña y el mismo Abel. En cuanto al profesor Negrín, cuya figura es objeto evidente de reivindicación, funciona en cierto modo como un contrapunto del protagonista. Al igual que Abel, se trata de un profesional prestigioso; sin embargo, frente al individualismo del arquitecto, Negrín aparece como un ejemplo de generosidad: en vez de salir del país en guerra y dedicarse en otro lugar más civilizado a la ciencia, decide implicarse en el conflicto por un imperativo cívico ineludible, lo cual no lo lleva a engañarse sobre la realidad. En el capítulo 18, Negrín critica la ceguera del partido socialista, dividido internamente y arrastrado por la palabrería leninista de Largo Caballero (443). Sus frases destacan por una lucidez que, a otra persona menos altruista, le habría impelido a abandonar el país a su suerte, como se aprecia en el siguiente fragmento:

Pero este es el país que tenemos, amigo mío, nada da mucho de sí, ni para lo bueno ni para lo malo. Media España no ha salido del feudalismo y nuestros compañeros del diario Claridad quieren acabar ya con la burguesía, que apenas existe. (447)

La secuencia en la que Negrín se encarga personalmente de abastecer a la columna de su hijo en la sierra es una clara muestra de la desestructuración de las instituciones. Sus comentarios sobre el intento de linchamiento de Antonio Machado y de Juan Ramón Jiménez (713) inciden en esta visión crítica de los excesos del bando leal. El personaje de Juan Negrín, sin embargo, no se engaña en torno a la imposibilidad de llevar a cabo un programa de reformas en el contexto de la guerra, sin ayuda de las democracias occidentales (819).

En cambio, la figura de Azaña no recibe el tratamiento del doctor Negrín. El presidente de la República aparece atrapado por su imagen, como si viviera más pendiente de una frase redonda que de su labor política (440). Su aislamiento receloso en el Palacio

${ }^{9}$ Son numerosos los críticos que subrayan el papel de las figuras históricas en esta novela (Iwasaki, 2009:12; Masoliver Ródenas, 2009:9; Pozuelo Yvancos, 2009:12-13). 
Nacional al comienzo de la guerra es todo un símbolo. El encuentro final con Ignacio Abel destila, no obstante, clarividencia y amargura por la huida progresiva de los mejores talentos (827).

El protagonista remite, sin duda, a esa minoría ilustrada que, durante la República, justificó la esperanza en la modernización del país. El personaje engarza, por tanto, con ese grupo generacional de talentos que, en los diferentes ámbitos de las artes, las letras y la ciencia, parecen estar en condiciones de acercar al país a Europa. Su percepción de la realidad circundante es a menudo clarividente. A este respecto, su charla en el capítulo 16 con Eutimio Gómez, el capataz con el que mantiene ciertos vínculos de infancia, pone de relieve la visión que ambos tienen de los acontecimientos: la deriva totalitaria de cierto sector del socialismo, la falta de respeto por las instituciones republicanas, las prisas suicidas de algunos sectores, en opinión de Abel; la necesidad de cambios palpables, según Eutimio. Ante las críticas del capataz, Ignacio Abel no puede evitar una actitud de cansada resignación: «Literatura de nuevo, pensaba, pero no lo dijo, por miedo a ofender a Eutimio. Literatura barata, morralla de periódicos...» (402). Su lucidez, sin embargo, lo impele a buscar una solución individual, persuadido íntimamente de la inutilidad de su sacrificio. Aceptar la oferta de trabajo en Estados Unidos implica no sólo acabar con esa doble vida que ha llevado durante el último año en Madrid y poder así reunirse con Judith, sino también encontrar un medio en el que la vida cotidiana sea más llevadera. El contraste con la actitud entregada de Negrín es evidente.

Como señala el presidente Azaña en un encuentro con el arquitecto (748-749), la búsqueda de una salida personal constituye una decisión compartida por muchos intelectuales. Algunos de ellos, en su opinión, aprovechando las prebendas oficiales, no dudan en huir del país. A este respecto, la novela ofrece una visión decepcionante de las elites. Cierto es que algunas figuras como Moreno Villa o el propio Negrín sirven de contrapunto; no obstante, la participación de Alberti y Bergamín es objeto de un cuestionamiento severo, alejado de la indulgencia con que se suele presentar su trayectoria. El relato subraya, particularmente en Bergamín, la intransigencia, el fanatismo ideológico (719-721), así como el apego a los privilegios de clase, en evidente contradicción con el discurso igualitario. La presentación de Alberti y señora en los preparativos de una fiesta de disfraces (760), mientras el enemigo se acerca a las puertas de Madrid, constituye un cuestionamiento en toda regla de su actitud. El caso de Ignacio Abel resulta muy interesante por la complejidad de su posición: por una parte, desprecia la actitud acomodaticia de estos intelectuales y su rigidez ideológica; por otro lado, sin embargo, huye del compromiso cívico con el país, arrastrado por el conflicto personal y familiar. En esta contradicción radica el atractivo del personaje.

\section{Algunos APUnTes FinAles}

La novela de Muñoz Molina, sin duda, constituye un referente entre las obras que abordan la guerra civil desde la perspectiva actual. Puede discutirse su carácter excesivo o algunas reiteraciones, todo lo cual no empaña, sin embargo, las numerosas virtudes de esta narración. Respecto a la cuestión del tiempo, es innegable su papel central en este relato: el escritor ha querido acercarnos a una época lejana de modo que podamos 
experimentar durante unas horas la sensación de vivir en aquel momento, subrayando los detalles cotidianos, la vida normal en un período histórico especialmente convulso.

Para ello, ha escogido una compleja estructuración cronológica, que combina, por una parte, cuatro niveles temporales básicos, a los que se añade una progresión cronológica sincopada, con frecuentes avances y retrocesos en forma de espiral. No obstante, la historia se centra en los meses previos al estallido de la guerra y en los primeros meses del conflicto. Es aquí donde el narrador intenta plasmar esa cotidianidad como un presente que ignora todavía el desastre. La perspectiva actual, no obstante, puntea de vez en cuando el relato, marcando así la dificultad que implica acercarse a una época tan lejana.

La frecuencia narrativa constituye también un acierto de esta novela: algunos hechos fundamentales se presentan de forma reiterada, lo que constituye, por un lado, un factor de tensión narrativa, y por otro, un recurso de profundización en la interpretación de la realidad. En cuanto al ritmo, es evidente la tendencia a una presentación morosa, en la que la descripción y la presentación escénica adquieren especial relevancia. De ahí se deriva un tipo específico de lectura, atenta al detalle y a la evolución de la frase.

En cuanto a la interpretación del tiempo, el autor profundiza en esta novela en una corriente valorativa de la guerra civil que rechaza de entrada los apriorismos ideológicos. Al hilo de la recuperación de la memoria histórica, el autor cuestiona los excesos de ambos bandos, con especial incidencia en la situación de la capital española, donde sitúa su relato. El deseo de entender la vida cotidiana de la época parece, por tanto, inseparable de esta voluntad expresa de no dejarse arrastrar por las preferencias políticas, subrayando así esa vida ordinaria al borde del desastre. Creo que éste es uno de los aspectos más destacados de la novela. Pero no puede desdeñarse tampoco la importancia del tiempo como dimensión interior de los personajes, particularmente del protagonista, ni la reflexión metanarrativa que acompaña el relato, dimensión inseparable de esa voluntad ética de abordar la historia con las armas de la ficción novelística.

\section{REFERENCIAS BIBLIOGRÁFICAS}

Astorga, Antonio (2009): «La noche de los tiempos», ABC, 2/12/09.

AYÉn, Xavi (2009): «Los héroes no sirven para construir una novela (Entrevista con Antonio

Muñoz Molina)», La Vanguardia, 24/11/09, p. 32.

BAL, Mieke (1987): Teoría de la narrativa, Madrid, Cátedra.

CARRIón, Jorge (2009): «La noche del realismo», Letras libres, noviembre, p. 54-55

GeNETTE, Gérard (1989): Figuras III, Barcelona, Lumen.

GenETTE, Gérard (1998): Nuevo discurso del relato, Madrid, Cátedra.

IwASAKI, Fernando (2009): «Antonio Muñoz Molina en Sevilla», $A B C$, 25/11/09, p. 12.

MASOliver RódenAS, Juan Antonio (2009): «Las voces de la ausencia», Cultura/s La Vanguardia, 18/11/09, p. 8-9.

MuÑoz Molina, Antonio (2009): La noche de los tiempos, Barcelona, Seix Barral.

Pozuelo Yvancos, José María (2009): «Adulterio. Madrid, 1936», ABC Cultural, 28/11/09, p. 1213.

VillanueVA, Darío (2010): «La hora del autor», Revista de libros, 158, febrero. 
